\title{
MicroRNAs biomarkers profiling in diagnosis and therapeutic management of hepatitis $B$ virus infection
}

\author{
Professor Dr. Sorush Niknamian \\ Member of Federal Dealth Professionals, Military Medicine, US Army, United States \\ E-mail: so.niknamian@gmail.com
}

\begin{abstract}
Introduction: Due to lack of unique method with high accurate and repeatable, assessment and even treatment of HBV infection and it,s complications such as cirrhosis and HCC has been with limitations. MicroRNAs (miRNAs) are small 19-24 nucleotide-long molecules with up-regulated and down-regulated Expression. The present research provides a narrative review expression profiling biomarkers miRNAs in diagnosis, treatment and differnciated CHB from cirrhosis or HCC.
\end{abstract}

Methods: We search database google scholar, pubmed, scopus, SID on English Languish article and also assess EASL and AASLD (2002-2016).

Results: Some of miRNAs are specifically more abundant in specific tissues, such as miR-122 in the liver. MiRNAs such as miRNA125a, miRNA141, miRNA1, miRNA197, miRNA122 and miRNA372, 373 have a major role in CBH and miRNA29a/b/c, miRNA200, miRNA199, miRNA133a, miRNA214 andmiRNA181b have a major role in fibrosis/cirrhosis. miR-106b and miR-181b, have a significant clinical diagnostic value in liver cirrhosis, especially at its early stages. miR-122, miR-192, miR-92, miR-223, miR-26a, miR-27a and miR-801, has a highly accurate diagnostic power that can differentiate HCC from $\mathrm{CHB}$ and cirrhosis and from healthy people as well as.

Conclusion: In the future, the miRNAs biomarkers provide researchers with a golden opportunity and can be used as early diagnostic and miRNAs based-therapeutic panels and current knowledge between miRNAs profiling biomarkers and progressive stage of HBV related diseases. Panels of miRNAs will play a significant role in decision-making about their proper course in both of treatment and diagnosis of diseases such as hepatitis B virus infection. Keywords: Chronic hepatitis B;Epidemiology; Heoatocellular Carcinoma (HCC);cirrhosis; microRNA, HBV, Treatment

Abrrevation: hepatitis B virus (HBV),MicroRNAs (miRNAs), chronic hepatitis B (CHB), hepatocellular carcinoma (HCC), European Association for the Study of Liver (EASL) and American Association for Study of Liver (AASLD) 


\section{Introduction}

Hepatitis B viral (HBV) infectionis considered the most common chronic viral infection and a major cause of acute and chronic liver disease and a significant health challenge throughout the world (1). According to the World Health Organization (WHO), almost one-third of the world's population is infected with hepatitis B virus and 240 million people suffer from chronic hepatitis B infection. More than 780,000 people die every year due to its complications, including cirrhosis and hepatocellular carcinoma (HCC). (2). Hepatitis B infection can be present asymptomatic, acute form , chronic or fulminant.The disease is diagnosed on the basis of an increase in liver enzymes including ALTAST and HBsAg positive or HBV DNA virology. This disease is treated with interferon and nucleotide/nucleosideanalogues(3). Treatment with interferon aims to create an antiviral response by the host's immune system to permanently control the infectionbut treatment with nucleotide analoguesaims only, to inhibit viral DNA production and reduce the number of infected hepatocytes (4). Despite the comprehensive vaccination programs and the favorable progress in the treatment of hepatitis B in many countries and the consequent dramatic decrease in its prevalence, the poor vaccination coverage and the failure todiagnose the infected in some countries have kept this disease a major global health concern and the global burden of hepatitis B thus remains high (5). In the early diagnosis of $\mathrm{HBV}$ and determining the time difference in the conversion of $\mathrm{CHB}$ complications to cirrhosis or HCC, one of the most important challenge is to be found. Labratoary tests such as ALT and HBV DNA have not always been effective. Liver biopsy is a golden standard method for liver pathological diagnosis with complication such as mortality and morbidity (6). Diagnostic tools such as CTSCAN, MRI have not been used in all applications and have not been satisfactory. Therefore, attention has to be paid to methods that can be simpler and less risky and feasible with less error. In recent years, the microRNAs biomarkers profile has been widely studied in various diseases including HBV(7). MicroRNAs (miRNA) are small non-coding RNA molecules with 19 to 24 nucleotides that regulate the post-transcription expression of genes as up/down-regulation by the decomposition or inhibition of the translation of the target messenger RNA (mRNA). MiRNAs are stable in plasma or serum suggesting potential use of noninvasive biomarkers (8). These molecules can be found in humans, animals, viruses, etc. The first miRNA, called Line-4, was discovered in a Caenorhabditis elegans nematode in 1993 and was needed for the further conversion of larval stages (9). MicroRNAs (miRNAs)form almost 3\% of the human genome and more than 2588 of them have been discovered to date (miRBase, Release21). MiRNAs participate in many biological activities of the cells, such as cell growth, proliferation and differentiation, apoptosis (programmed cell death), inflammation, metabolism, suppression and disease or cancer. Most miRNAs are coded in the inner parts of genes while some are coded in the opposite direction, i.e. antisense coding. A miRNA can sometimes target several genes (10).

We discuss about of these small, stable and conserved biomarkers provide researchers can be used as early diagnostic and miRNAs based-therapeutic panels and current knowledge between miRNAs profiling biomarkers and progressive stage of HBV related diseases.

\section{Methods}

\subsection{Search strategy}

A narrative review search was performed using citation databases of pubmed and Scopus, SID. Keywords included hepatitis B, epidemiology, transmission, virology, miRNA, CHB, $\mathrm{HBV}$, alone and combined. We also searched European Association for the Study of Liver (EASL) and American Association for Study of Liver Disease (AASLD) on base Englisg Languigh in period 2002 up to September 2017. The search strategy was evaluated using the search method of a professional library and using text keywords that were controlled by the 
Medical Subject Heading (MESH) and key words. Key words include "HBV "Chronic hepatitis B (CHB) "Heoatocellular Carcinoma (HCC) "MicroRNAs ", miRNAs "Profileing microRNA" Treatment " and articles that describe the microRNA profile in hepatitis B patients and their complications, such as CHB and cirrhosis, fibrosis and HCC. Papers on the importance of the plasma microRNAs in the diagnosis of $\mathrm{HBV}$ and the differentiation of the complications of the disease from each other or the therapeutic aspect was also studied.

\subsection{Inclusion criteria}

Inclusion criteria were English language studies, cross-sectional studies, cohort studies, randomized control trials, as well as reviews. All applicable studies were evaluated based on titles and abstracts.

\section{The production and functions of microRNAs}

MicroRNAs are produced in a series of stages: First, polymerase II is transcribed from the gene and thus produces 100-nucleotide hairpin-shaped precursors (pri-miRNAs). Next, a shorter structure of 60-70 nucleotides called the pre-miRNA is produced inside the nucleus by Drosha/RNase III and with the help of Pasha/DGCR8 (11). In the next stage, this structure enters the cytoplasm with the help of Exportin-5, a membrane protein;where thedoublestranded molecule is converted into an miRNA of 22-24 nucleotides by another enzyme called Dicer/RNase III (12). Another complex called RNA Induced Silencing Complex (RISC) then makes the double-stranded pre-miRNA single-stranded. If this strand binds partially to a particularregion of the gene in the three prime untranslated region (3'-UTR), it stops the translation of mRNA into protein, and mRNA is fully abrogated if miRNA is fully paired. Most studies argue that the other strand is lost, but in most cases, there is evidence that both strands remain active (13).

\section{The natural history of chronic hepatitis}

4.1. Acute hepatitis Viral hepatitis emerges in chronic and acute forms. In acute mode, the incubation period often lasts between six weeks and six months. The symptoms of this disease include weakness, nausea, and vomiting, abdominal pain, loss of appetite, jaundice, dark urine and joint pain, which may last more than several weeks. Chronic hepatitis is defined as a longterm necroinflammatory disease caused by hepatitis B virus; theHBSAg test remains positive in patients for over six months and is divided into positive and negative HBeAg groups.HBVDNA titration reaches $10^{5}$ copies per $\mathrm{ml}$ of serum, or the equivalent of $20,000 \mathrm{IU} / \mathrm{mlin}$ the $\mathrm{HBeAg}^{+}$group and between 2000 and $20,000 \mathrm{IU} / \mathrm{ml}$ in the $\mathrm{HBeAg}^{-}$group, the ALT/AST ratio increases and signs of chronic hepatitis, inflammation and necrosis emerge in the liver biopsy. However, serum ALT drops significantly if the hepatocytes are severely damaged (14). As previously noted, more than $90 \%$ of infections occur in newborns less than one year oldand about $5 \%$ of the adult cases of infection ultimately become chronic. Most chronic cases of this infection are transmitted from infected mothers to infants at birth or in the first year of life $(15$, 16). HBsAg positive pateints has a wide range in countries between low $(<2 \%)$ and high $(>8 \%)$ (17). Iran is located in a low endemic area $(<2 \%)$. The prevalence of hepatitis B has been reported as $1.3 \%$ in general population and among Iranian men is 3\% and as $1.7 \% \%$ among Iranian women (18). Controlling the main risk factors of the infection and emphasizing the new ones emerging, such as tattoo, intravenous injections, the use of non-sterile medical tools and frequent injections in thalassemia and dialysis patients are highly important. Given the reduced immunitydue to adult vaccination, it is highly recommended to extend hepatitis vaccination coverage to age 35 and to implement programs to increase awareness and better control the disease in endemic regionsso as to obviate the burden of the disease. Statistical findings suggest that nearly 1.5 million people live with hepatitis in Iran. Cirrhosis and hepatocellular carcinoma 
are the main complications of hepatitis B and perhaps the ultimate torturous outcome in patients. Nevertheless, early medical and medicinal interventionscan help prevent the rapid progress of the disease toward HCC. (19-21). The likelihood of the disease becoming chronic is inversely associated with age. Almost $90 \%$ of children born to infected mothers will develop chronic infections if not vaccinated, but the rate drops to $30 \%$ in early childhood and to less than 5\% in adulthood (22). Mir-106b, belonging to the miR-106B-25 cluster, is proven to have a major physiologic and pathophysiologic role in controlling the apoptosis of liver cells and performs this role as the negative post-transcription expression of several genes, such as TGF$\beta$ and p21/CDKNIA(23). Wen Chen conducted a study between 2008 and 2011 to assess the profile of micros in 104 patients diagnosed with Acute-Chronic Liver Failure (ACLF) and 76 patients diagnosed with Asymptomatic Carrier (AsC) and extracted miRNAs from PBMC samples. Out of the four miRNAs extracted (hsa-let-7a, hsa-let-7i, hsa-miR-16 and hsa-miR17) with up-regulated expressions; hsa-miR-16 and hsa-let-7a had a greater up-regulated expression in patients with ACLF compared to in the AsCs. The results obtained showeda close relationship between PBMC-specific microRNAs and the miRNAs causing ACLF while no significant differences were observed between the two groups in terms of hsa-let-7i and hsamiR-17 (24). Circulating miRNAs are non-invasive biomarkers of diagnostic tool, recently, in particular miRNA 122 was illustrated a new biomarker of acute liver injery in mice. Though miRNA are very sta ble molecules in serum or plasma, for better comparability and reproducibility in future studies, a well-standardized protocol is needed, in order to evaluate miRNAs as biomarkers for acute hepatitis

\subsection{Chronic hepatitis}

Chronic hepatitis is divided into four phases. A: The Immune TolerantPhase: This phase occurs mostly after neonatal infection transmitted through a mother with positive $\mathrm{HBsAg} / \mathrm{HBeAg}$. ALT level is often normal in this phase, but HBVDNA is replicated to more than one million copies. Liver biopsy is either normal or slightly inflammatory or is reported with minimal fibrosis or without fibrosis. The duration of this phase is highly variable, but is longer in people who have been infected in their neonatal period. HBeAghelps inhibit the detection of the virus by the immune system and is mostly observed in genotype C.Due to the high proliferation rate of the virus, chances of transmission are high. B: The Immune Active Phase (spontaneous clearing): In this phase, there are laboratory signs of the immune tolerant phase; ALT and HBVDNAlevels increase $(\geq 20,000 \mathrm{IU} / \mathrm{ml})$ and $\mathrm{HBeAg}$ is positive. The proliferation of the virus is relatively lower in this phase compared to in the immune tolerant phase. The spontaneous clearing of HBsAg may occur in $1 \%$ to $3 \%$ of the infected every year.Anti-HBe is positive and the immune system identifies the virus as a foreign invader that causes moderate to severe damage to the liver tissue. C: The Inactive Carrier Phase: Characteristics: ALT remains at the ultimate normal level $(40 \mathrm{IU} / \mathrm{ml})$ and HBVDNA $(<2000$ $\mathrm{IU} / \mathrm{ml}$ ) is reduced or undetectable, and anti-HBe becomes positive.In histological terms, the liver shows minimal necroinflammation. D: The Reactivation Phase (HBeAg-): In this phase, ALT and HBVDNA increase ( $\geq 2000 \mathrm{IU} / \mathrm{ml}$ ) and the liver tissue undergoes fibrosis and inflammation. In this phase, hepatitis B virus may become reactivated and thus exacerbate the disease in $10 \%$ to $20 \%$ of the inactive carriers. The liver undergoes fibrosis and inflammation andHBVDNA levels should be examined every three or four months and ALT levels every six months (after the first year) (25-27). MiRNAs potentially contribute to the diagnosis of chronic hepatitis complications, such as silent cirrhosis. Two miRNAs, namely miR-106b and miR$181 \mathrm{~b}$, have a significant clinical diagnostic value in liver cirrhosis, especially at its early stages (6). Studies conducted on serum miRNA in different phases of chronic hepatitis B and during treatment with anti-viral medications show that miRNAs are effective in both the normal course of the disease and during treatment;as miR-B index is an effective biomarker for the early 
diagnosis of patients with chronic hepatitis treated with anti-viral medications and progressing toward passive hepatitis (28). The down-regulated expression of miR-122 obtained from the liver biopsy of patients with advanced cirrhosis and its relationship with fibrosis stages and liver stiffness can be a particular characteristic of hepatic fibrosis caused by a number of reasons (29).

5.3 Liver cirrhosis is another complication of chronic hepatitis in which the damaged liver loses its function. Cirrhosis is derived from a Greek word meaning 'yellowish'; in histological terms, it is defined as the development of regenerative nodules surrounded by fibrous strands. Cirrhosis is divided into compensated and decompensated categories and leads to a wide range of symptoms and complications in patients, including ascites, jaundice, encephalopathy, splenomegaly and ultimately hepatocellular carcinoma (30).In spite of the risks involved (such as liver bleeding and inaccurate pathological diagnosis), liver biopsy is currently the best diagnostic toolthat reports the grade and stage of the tissue inflammation, necrosis and fibrosis. Stage F4 is regarded as cirrhosis. Given the presence of ascites and bilirubin, albumin and encephalopathy, the severity of the cirrhosis, disease prognosis and potential need for liver transplantation are determined according to the Child-Pugh scale; this scale has three classes (A, B and C), with 5-6 points indicating class A, 7-9 points indicating class B and 10-15 points indicating class $\mathrm{C}$ (31). The mortality rate of cirrhotic patients is determined using the Model for End Stage Disease (MELD), which is based on a mathematical equation that helps calculatecreatinine levels, the International Normal Ratio (INR) and bilirubin through laboratory tests (32). FibroScan measures liver stiffness and helps with the diagnosis of the disease, but it has a limited application in cases such as obesity, ascites and small intercostals spaces. Other commonly-used devices for the follow-up of patients include CT scan, ultrasound and MRI (33).. The role that miR-181b plays in the progress of the disease and HBVDNAlevels in patients with chronic hepatitis B demonstrates one of these capacities that eliminate the need for a liver biopsy. MiR-181b is said to activate the hepatic satellite cells and increase in the serum of cirrhotic patients; it is up-regulated in CHB patients compared to healthy people and is associated with the proliferation of HBVDNA virus and the progress of the disease, which indicatethepotential importance of this marker in the independent prediction of the progress of chronic hepatitis B (34).

5.4 Hepatocellular carcinoma is a malignant liver tumor that develops mostly in cirrhotic patients. This carcinoma is the second and common leading cause of cancer-related deaths across the world, claiming almost 5210,000 lives every year (35). Viral infections with hepatitis $\mathrm{B}$ and $\mathrm{C}$ are the main causes of this carcinoma. Ultrasound, CTscan and MRI are used for diagnosing this disease. The $\alpha$-fetoprotein test is also currently used as a diagnostic biomarker test, although it lacks full sensitivity and specificity. Cancerous tumorsof the liver are classified according to the Barcelona Clinic Liver Cancer (BCLC) staging system and using tumor grade, cirrhosis stage and liver function indices, which are later used in deciding the right course of treatment for the patient. Stage zero is the initial stage of cancer and has the best prognosis. Other stages include A, B, C and D and also the terminal stage, which has the worst prognosis $(36,37)$. The detection of plasma miRNAs in HCC patients caused by hepatitis B virus is also highly important. Zhou Jian et al. found a panel of miRNAs that was distinctively able to diagnose early-stage HCC patients; it may be therefore effective in the treatment of patients who may be missed in the window of cure. The results obtained from previous studies show that this panel, which includes miRNAs such as miR-122, miR-192, miR-92, miR-223, miR26a, miR-27a and miR-801, has a highly accurate diagnostic power that can differentiate HCC from $\mathrm{CHB}$ and cirrhosis and from healthy people as well as (38). As early diagnosis of HCC 
can improve the survival rate, a novel diagnostic method to discriminate liver disease stages, circulating miRNAs have potential test as a tool of diagnosis.

\section{Treatment}

Hepatitis B virus is an enveloped hepatotropic virus with small double-stranded DNA of 42nm-diameter and 3.2-kbp-length (equivalent of 3200 open pairs) belonging to the Hepadnaviridae family (39). Viruses proliferate by reverse transcription in the liver cells; however, they do not directly affect cells. DNA virus enters the nucleus, forming the ringshaped Covalently Closed Circular DNA (cccDNA), which is similar to a small chromosome and is used as a template for mRNA synthesis. In the presence of cccDNA, antiviral medications that inhibit virus synthesis cannot create full recovery; rather, they delay damage to the liver cells (40). In the last few decades, $\alpha$-interferon has been used for the treatment of patients; however, the new double formula of PEG-INFisconsidered a standard treatment. Six nucleotide and nucleoside medications have also been added to the treatment panel of chronic hepatitis, includingTenofovir, Telbivudine, Adefovir, Entecavir, Lamivudine and Emtricitabine, each with its different effectiveness. In most studies, the preferred duration of treatment with PEG-INF is 48 weeks, although itdiffers for $\mathrm{HBeAg}^{+}$patients treated with oral anti-viral medicationsand depends on biochemical and virology markers and is recommended to be continuedfor 6 to12 months even after the normalization of ALT, the disappearance of $\mathrm{HBeAg}$, the emergence of anti-HBe and the non-detection of HBVDNA. Treating patients with analogue nucleotide medications requiresa greater attention to liver creatinine clearance. Surgical and non-surgical methods and ultimately transplantation are used for the treatment of complications such as hepatocellular carcinoma and end-stage cirrhosis $(41,42)$. (Table 1)

\section{8..Discussion}

MiRNAs have opened a promising new chapter for researchers in various diagnostic and treatment fields. These biomarkers act as a double-edged sword and will significantly contribute to science in the near future, since down-regulated and up-regulated expression are both associated with specific conditions in living creatures. Some miRNAs are more specifically present in certain tissues, such as miRNA-122 in the liver and miR-133a/b in the muscle cell. In addition to their intracellular presence, a number of miRNAs can also be found in bodily fluids such as urine, saliva and plasma. Characteristics such as conservation, endurance and stability and the ability to control hundreds of genes, which is considered an advantage, have favoredthem as a diagnostic test for some markers such as ALT in the assessment of liver or as miR-499 in the assessment of myocardial infarction $(43,44)$. Considering the extensive research currently being conducted on miRNAs, it should be admitted that, by way of unique characteristics such as mRNA inhibition or destruction, which affect gene expression through a negative control mechanism, these small, stable and conserved biomarkers provide researchers with a golden opportunity and can be used as early diagnostic panels and in decision-making about the treatment process to take before hepatitis progresses into deadly complications such as cirrhosis and liver carcinoma $(45,46)$. Their therapeutic importance has recently been proven with the synthesis of miRNA antagomir Most powerful diagnostic tools currently existing, such as AST and ALT, whichare also found in other diseases, cannot significantly help determine the grade or stage of complications related to hepatitis B or decide about treatment options. In many advanced cases, these enzymes are within the normal range or slightly deviate from it, and due to the AFP test's lack of adequate sensitivity and specificity, delays in diagnosing HCC are also considered a cause of the high 
mortality rates associated with this disease. These tests cannot differentiate between someone with chronic hepatitis, someone who has recently developed cirrhosis, or a chronic hepatitis B carrier. Radiological techniques such as ultrasound, CTscan and MRI show little diagnostic accuracy when the lesions are very small. As stated earlier, although liver biopsy is considered the gold standard, its invasive nature and the associated risk of bleeding and infectionand the likelihood of wrong pathology reports and wrong tissue samples make physicians more doubtful about the proper course of treatment. FibroScan does not have the necessary efficiency in every stage $(44,47,48)$. Previous studies have shown that, in addition to their regulatory role in cells, miRNAs are also involved in many human diseases such as those associated with hepatitis B virus. By modulating the proliferation of the hepatitis virus, regulating the formation of extracellular matrix and silencing tumor-suppressor genes, these small molecules contribute to infection with chronic hepatitis B and the development of complications, including cirrhosis, fibrosis and hepatocellular carcinoma. As both diagnostic markers and fetal therapy, these molecules are considered appropriate tools for the diagnosis of hepatitis and the treatment of its complications.

\section{1: microRNAs as diagnostic and prognostic roles in CHB, HCC, Cirrhosis}

MiRNAs such as miRNA125a, miRNA141, miRNA1, miRNA197, miRNA122 and miRNA372, 373 have a major role in CBH and miRNA29a/b/c, miRNA200, miRNA199, miRNA133a, miRNA214 and miRNA181b have a major role in fibrosis/cirrhosis. Given the stability of these molecules in the blood circulation and their specific detection in hepatic patients, discovering their relationship with the virus genome promises the use of this method as a better way of eliminating cccDNA, which is considered a major challenge in the treatment of patients (49). In many patients with hepatitis B infection, the expression of miRNAs in serum or tissue samples can be up-regulated or down-regulated. For instance, comparing the expression of the miRNA-101 profile in the serum and liver tissue samples of patients with chronic hepatitis, cirrhosis and hepatocellular carcinoma and in the samples taken from a healthy control group shows a down-regulated expression of microRNA-101 in HCC patients compared to the other three groups. However, not only is the expression of miR-101 in patients with liver cirrhosis not down-regulated compared to in patients withCHB and healthy controls, it is also up-regulated in the serum and liver tissue samples. Researchers intending to use these panels in the future as a modern diagnostic technique in or even in treatment follow-up and disease prognosis should ensure that the test has an acceptable sensitivity and specificity. The validity of these tests is often assessed using the Receiver Operating Characteristics (ROC) and the Area under ROC Curve (AUC). The results of the present study showed that this biomarker has a favorable diagnostic power for monitoring $\mathrm{HCC}$ infection in cirrhotic patients and liver cirrhosis infection in chronic hepatitis patients (50).It should be noted that miRscan be used as a potential marker in identifying liver pathologies and also in optimizing the clinical experience. The expression levels of miR-885-5b were found to be much higher in the serum of patients with cirrhosis, chronic hepatitis and hepatocellular carcinoma. It is possible that other laboratory markers such as GGT, AFP, AST and ALT are not related to the up-regulated expression of miR-885-5b in patients with liver damage. Nevertheless, this biomarker can be used as a supplementary biomarker in the assessment and detection of liver pathologies associated with hepatitis B (51). In a study conducted by Bo-XunJin et al. between 2009 and 2013 on 495 people divided into three groups of 165 and consisting of healthy controls and patients with chronic hepatitis and liver cirrhosis, which was performed in several phases, including the discovery phase, the training phase, the validation phase and the blinded test phase, the logistic regression analysis showed that the expression of some of these biomarkers was related to HBVDNA and liver function tests, including albumin (ALB), ALT and Cholinesterase (CHE) tests. Out of the 53 miRNAs in this study, 10 miRNAs were used for 
detecting cirrhosis, including miR-27a-3p, miR-451a, miR-1, miR-18a-5p, miR-29c-3p, miR106b-5p and miR-185-5p, and three for both CHB and liver cirrhosis, including miR-21-5p, miR-122-5p and miR-146a. Based on the data obtained by the specifically-designed panel, a new diagnostic tool was used for differentiating healthy people from patients with chronic hepatitis and cirrhosis. The sensitivity and specificity of this panel were reported as $85 \%$ and $70 \%$,respectively (52). The use of the comprehensive expression of the miRNA present in peripheral blood exosome for the diagnosis of liver diseases has also been tested. The exosome in the endoplasmic reticulum network can carry mRNAs and miRNAs. RNA is extracted using microarray and real-time qPCR analysis. The results of the miRNA expression can then be used to compare with thegrading and staging of chronic hepatitis, which are determined through blood and histology tests. The histological grading and staging of biopsies are performed using the METAVIR classification system. The differences between the initial phase of fibrosis and the final inflammation grade can be understood with the help of a group of miRNAs. These panels are even recommended to be used in the staging and grading of fibrosis (53).As mentioned earlier, for various reasons such as the patient's unwillingness, bleeding, and the.lack of sufficient tissue sample for pathology tests and poor results, gastroenterology and hepatology specialists do not recommend taking liver biopsies from patients in many cases. Certain miRNAs, such as miR-124, strongly appear in the necroinflammation of the liver tissue and can thus be used in grading and staging. MiR-124 has been found to serve as a non-invasive biomarker in the diagnosis of moderate to severe liver necroinflammation. Moreover, there is a positive relationship between interleukin-10 and up-regulated miR-124. It is worth noting that miR-124 is down-regulated in patients treated with entecavir for 48 weeks, which is also associated with histopathological recovery (54). One of the criteria for the treatment of chronic hepatitis and cirrhosis is the amount of virus in the patient's serum and treatment is initiated or discontinued according to this amount. The capacities of miRNAs can also be used in relation to the progress of the disease. The ultimate question of whether or not plasma miRNAs have a diagnostic value in identifying diseases associated with hepatitis B can be answered by extensive research in the future, but the studies conducted to date are also promising and satisfactory. Two models of study, namely human and animal models, have used liver biopsy to determine necrosis and fibrosis levels. Of the eight miRNAs studied, miR-122 had the highest up-regulated expression in human and animal samples. The researchers have therefore concluded that this miRNA can have a major role as a new, reliable and predictive biomarker of the factors causing liver damage, such as alcohol, chemicalsand viruses (55). By the same token, miR-143 and miR-215 are demonstrated to serve as diagnostic biomarkers in patients with $\mathrm{CHB}$ and $\mathrm{HCC}$ and in healthy people, and miR-215 has an up-regulatedexpression in CHB patients compared to in healthy people. Statistical findings suggest that both these miRNAs have a significant sensitivity and specificity in patients with hepatocellular carcinoma and chronic hepatitis and can potentially be considered as diagnostic biomarkers (56). MicroRNAs panels are reliable and sensitive to discriminate HCC patients from non HCC individuals who infected with HBV OR HCV .Panels of miRNAs can produce results than single miRNA diagnosis (57). The main issue that remains is that these panels cannot have a perfect sensitivity and specificity in all populations, which may be due to genetic and physiological differences among people $(58,59)$. Tabele 2 : Resultes of many Meta - Analysis

\section{Conclusion}

Given the noted differences, local studies need to be conducted in every region. Nevertheless, the identification and study of this miRNA in patients with hepatitis B virus will serve as a 
good terminator or queen, since different studies have reported apromising role for it in the early diagnosis of different forms of chronic hepatitis and for grading and staging the disease and determining the patients' clinical conditions. Overall, it appears that miRNAswill play a significant role in the future in both the diagnosis of diseases such as hepatitis B and in decision-making about their propercourse of treatment.

Conflict of Interest: There is no conflict of interest to be declared.

\section{References:}

1. D. L. Hepatitis B virus epidemiology, disease burden, treatment, and current and emerging prevention and control measures. Journal of Viral Hepatitis. 2004;11(2):97-107.

2. World Health Organization (WHO).Hepatitis B, Fact sheet $\mathrm{N}^{\circ} 204$. 2015 May.

3. Piero L. Almasioa SB, Giorgio Barbarinic, Maurizia Brunettod, Dario Conte and et.al. Recommendations for the prevention, diagnosis, and treatment of chronic hepatitis $\mathrm{B}$ and $\mathrm{C}$ in special population groups (migrants, intravenous drug users and prison inmates). Digestive and Liver Disease. 2011;43:589- 95.

4. Wong GL, Wong VW, Chan HL. Combination therapy of interferon and nucleotide/nucleoside analogues for chronic hepatitis B. J Viral Hepat. 2014 Dec;21(12):82534. PubMed PMID: 25402543. Epub 2014/11/18. eng.

5. Christian Trépo HLYC, Anna Lok. Hepatitis B virus infection. Lancet. 2014;384:205363.

6. Chen YJ, Zhu JM, Wu H, Fan J, Zhou J, Hu J, et al. Circulating microRNAs as a Fingerprint for Liver Cirrhosis. PLoS One. 2013;8(6):e66577. PubMed PMID: 23805240. Pubmed Central PMCID: PMC3689750. Epub 2013/06/28. eng.

7. Filipowicz W, Jaskiewicz L, Kolb FA, Pillai RS. Post-transcriptional gene silencing by siRNAs and miRNAs. Current opinion in structural biology. 2005 Jun;15(3):331-41. PubMed PMID: 15925505. Epub 2005/06/01. eng.

8. Robin C. Friedman KK-HF, 1,2,4 Christopher B. Burge,, Bartel1 DP. Most mammalian mRNAs are conserved targets of microRNAs. Genome Resby Cold Spring Harbor Laboratory Press. 2009;19:92-105. Pubmed Central PMCID: PMID: 18955434

PMCID: PMC2612969.

9. Rosalind C. Lee tRLF, Ambros V. The C. elegans Heterochronic Gene lin-4 Encodes Small RNAs with Antisense Complementarity to \&II-14. cell. 1993;75: 843-54.

10. Slack AE-KaFJ. Oncomirs - microRNAs with a role in cancer. NATURE REVIEWS | CANCER. 2006;6:259-69.

11. Paul Graves YZ. Biogenesis of Mammalian MicroRNAs: A Global View. Genomics Proteomics Bioinformatics. 2012;10(5):239-45. Pubmed Central PMCID: PMID: 23200133

PMCID: PMC5054211.

12. Chimari Okada EY, Soo Jae Lee, Satoshi Shibata, Jun Katahira, Atsushi Nakagawa,. A High-Resolution Structure of the Pre-microRNA Nuclear Export Machinery. Science 27 Nov 2009. 27 Nov 2009;326(5957): 1275-9. Pubmed Central PMCID: PMID 19965479. 
13. Hu HY1 YZ, Xu Y, Hu H, Menzel C, Zhou YH, Chen W, Khaitovich P. Sequence features associated with microRNA strand selection in humans and flies. BMC Genomics. 2009; 10(413):1-11. Pubmed Central PMCID: PMID:19732433.PMCID: PMC2751786.

14. Tong MJ, Hsu L, Chang PW, Blatt LM. Evaluation of current treatment recommendations for chronic hepatitis B: a 2011 update. J Gastroenterol Hepatol. 2011 May;26(5):829-35. PubMed PMID: 21214888. Epub 2011/01/11. eng.

15. Chen Szu-Ming KC-M, Yang Wen-Jena, Wang Hai-Lung. Efficacy of the nationwide hepatitis B infant vaccination program in Taiwan. Journal of Clinical Virology. 2011;52:11-6. Pubmed Central PMCID: PMID:21767983.

16. Wan-Hsin Wen M-HC, Lu-Lu Zhao, Yen-Hsuan Ni, Hong-Yuan Hsu, Wu J-F. Mother-to-infant transmission of hepatitis B virus infection: Significance of maternal viral load and strategies

for intervention. Journal of Hepatology. 2013;59:24-30. Pubmed Central PMCID: PMID:23485519.

17. EASL 2017 Clinical Practice Guidelines on the management of hepatitis B virus infection. J Hepatol. 2017 Aug;67(2):370-98. PubMed PMID: 28427875. Epub 2017/04/22. eng.

18. Salehi-Vaziri M, Sadeghi F, Almasi Hashiani A, Gholami Fesharaki M, Alavian SM. Hepatitis B Virus Infection in the General Population of Iran: An Updated Systematic Review and Meta-Analysis. Hepatitis monthly. 2016 Apr;16(4):e35577. PubMed PMID: 27257428. Pubmed Central PMCID: PMC4888501. Epub 2016/06/04. eng.

19. Alavian SM. Hepatitis B virus infection in Iran; Changing the epidemiology. Iranian Journal of Clinical Infectious Diseases. 2010;5(1):51-61.

20. McMahon BJ. Chronic Hepatitis B Virus Infectio Med Clin N Am. 2014;98:39-54. Pubmed Central PMCID: PMID:24266913.

21. Chen HL, Chang CJ, Kong MS, Huang FC, Lee HC, Lin CC, et al. Pediatric fulminant hepatic failure in endemic areas of hepatitis B infection: 15 years after universal hepatitis B vaccination. Hepatology. 2004 Jan;39(1):58-63. PubMed PMID: 14752823. Epub 2004/01/31. eng.

22. J.J. Otta GAS, J. Groegerb, S.T. Wiersma. Global epidemiology of hepatitis B virus infection: New estimates of age-specific HBsAg seroprevalence and endemicity. Vaccine. 2012;30:2212- 9. Pubmed Central PMCID: PMID:22273662.

23. Wu H WF, Hu S, Yin C, Li X, et al. MiR-20a and miR-106b negatively regulate autophagy induced by leucine deprivation via suppression of ULK1 expression in C2C12 myoblasts. Cell Signal 2012;24: 2179-86.

24. Wen Chen Z-HY, Yu-Ming Wang, Bao-Yan Xu and Guo-Hong Deng. Genome-wide microarray-based analysis of miRNAs expression in patients with acute-on-chronic liver failure. Hepatobiliary Pancreat Dis Int. 2014;13(1):32-9. Pubmed Central PMCID: PMID:24463077

25. European Association for the Study of the Liver (EASL) Clinical Practice Guidelines: Management of chronic hepatitis B virus infection. J Hepatol 2012 Jul;57(1):167-85. 2012;57:167-85. Pubmed Central PMCID: PMID:28427875.

26. Norah A. Terrault NHB, 2 Kyong-Mi Chang,3 Jessica P. AASLD Guidelines for Treatment of Chronic Hepatitis B. American Association for the Study of Liver Diseases HEPATOLOGY 
(AASLD). 2016;63(1):261-83. Pubmed Central PMCID: PMID:26566064.

27. McMahon BJ, Holck P, Bulkow L, Snowball M. Serologic and clinical outcomes of 1536 Alaska Natives chronically infected with hepatitis B virus. Ann Intern Med. 2001 Nov 06;135(9):759-68. PubMed PMID: 11694101. Epub 2001/11/06. eng.

28. Maurizia Rossana Brunetto DC, Filippo Oliveri, Francesco Moriconi,, Piero Colombatto BCaea. A Serum MicroRNA Signature Is Associated with th Immune Control of Chronic Hepatitis B Virus Infection. PLoS ONE 2014;9(10):e110782. Pubmed Central PMCID: PMID: 25350115

PMCID: PMC4211710.

29. Tünde Halász GH, Gabriella Pár, Klára Werling, András Kiss, Zsuzsa Schaff, Gábor Lendvai. miR-122 negatively correlates with liver fibrosis as detecte by histology and FibroScan. World J Gastroenterology 2015 July 7;21(25): 7814-23.

30. Jacob A. Udell M, MPH, FRCPC; Charlie S. Wang, MD, MSc, FRCPC; Jill Tinmouth, MD, PhD, FRCPC; J. Mark FitzGerald, MB, FRCPC; et,al. "Does this patient with liver disease have cirrhosis?". JAMA: the Journal of the American Medical Association. 2012;307(8):83242.

31. Ying Peng XQ, Junna Dai, Hongyu Li, Xiaozhong Guo. Child-Pugh versus MELD score for

predicting the in-hospital mortality of acute upper gastrointestinal bleeding in liver cirrhosis. Int J Clin Exp Med. 2015;8(1):751-7. Pubmed Central PMCID: PMID: 25785053

\section{PMCID: PMC4358508}

32. Wiesner RH. Evidence-based evolution of the MELD/PELD liver allocation policy. Liver transplantation : official publication of the American Association for the Study of Liver Diseases and the International Liver Transplantation Society. 2005 Mar;11(3):261-3. PubMed PMID: 15719393. Epub 2005/02/19. eng.

33. Detlef Schuppan and Nezam H. Afdhal. Liver Cirrhosis. Lancet. 2008;371(9615): 83851. Pubmed Central PMCID: PMCID: PMC2271178.

34. Fujun Yu GZ, Guojun Li, Bicheng Chen, Peihong Dong, Jianjian Zheng. Serum miR$181 \mathrm{~b}$ Is Correlated with Hepatitis B Virus Replication and Disease Progression in Chronic Hepatitis B Patients. 2015;60:2346-52. Pubmed Central PMCID: PMID:20930130.

35. Stewart BW WC. World Cancer Report 2014. World Health Organization. 2014 (In Press).

36. Bellissimo F, Pinzone MR, Cacopardo B, Nunnari G. Diagnostic and therapeutic management of hepatocellular carcinoma. World J Gastroenterol. 2015 Nov 14;21(42):1200321. PubMed PMID: 26576088. Pubmed Central PMCID: PMC4641121. Epub 2015/11/18. eng.

37. Wei-Yu Kao M, Yee Chao, MD, PhD, Chun-Chao Chang, MD, Chung-Pin Li, MD, $\mathrm{PhD}$, Chien-Wei Su, MD, PhD, Teh-Ia Huo. Prognosis of Early-Stage Hepatocellular Carcinoma: The Clinical Implications of Substages of Barcelona Clinic Liver Cancer System Based on a Cohort of 1265 Patients. Medicine. October 2015;94(43):e1929. Pubmed Central PMCID: PMCID: PMC4985433.

38. Jian Zhou LY, Xue Gao, Jie Hu, Jiping Wang, Zhi Dai. Plasma MicroRNA Panel to Diagnose Hepatitis B Virus-Related Hepatocellular Carcinoma. JOURNAL OF CLINICAL ONCOLOGY. 20 2011;29(36):4781-8. Pubmed Central PMCID: PMID: 22105822. 
39. Christoph Seeger $\mathrm{n}$ WM. Molecular biologyofhepatitisBvirusinfection. Virology. 2015;479(480):672-86. Pubmed Central PMCID: PMID:2575909 PMCID:PMC4424072.

40. Hu J, Seeger, C. Hepadnavirus genome replication and persistance. . Cold Spring Harb Perspect Med. 2015;5(7). Pubmed Central PMCID: PMID:26134841 PMCID:PMC4484952

41. Liaw YF, Jia JD, Chan HL, Han KH, Tanwandee T, Chuang WL, et al. Shorter durations and lower doses of peginterferon alfa-2a are associated with inferior hepatitis $\mathrm{B}$ e antigen seroconversion rates in hepatitis B virus genotypes B or C. Hepatology. 2011 Nov;54(5):1591-9. PubMed PMID: 22045673. Pubmed Central PMCID: PMID:22045673. Epub 2011/11/03. eng.

42. McMahon BJ. The natural history of chronic hepatitis B virus infection. Hepatology. 2009 May;49(5 Suppl):S45-55. PubMed PMID: 19399792. Epub 2009/04/29. eng.

43. Chen X BY, Ma L, Cai X, Yin Y, Wang K, Zhang CY and et.al . Characterization of microRNAs in serum: a novel class of biomarkers for diagnosis of cancer and other diseases. Cell Research. 2008;18(10):997-1006. Pubmed Central PMCID: PMID: 19732433 PMCID: PMC2751786.

44. Alton Etheridge IL, Leroy Hood, David Galas, and Kai Wang. Extracellular microRNA: a new source of biomarkers. Mutat Res. 2011;717(1-2): 85-90. Pubmed Central PMCID: PMID: 21402084 PMCID: PMC3199035

45. Teruyuki Ueda MH, Katsuhisa Horimoto c, Sachiyo Aburatani c, Shigeru Saito and et.al,. Gene expression profiling of hepatitis B- and hepatitis C-related hepatocellular carcinoma using graphical Gaussian modeling. Genomics Proteomics Bioinformatics. 2013;101(6): 238-48. Pubmed Central PMCID: PMID: 23485556.

46. Chakravarty NSaR. Hepatitis B Virus Infection, MicroRNAs and Liver Disease. International Journal of Molecular Sciences. 2015;16:17746-62.

47. Tara Behne MSC. Biomarkers for Hepatocellular Carcinoma. International Journal of Hepatology. 2012; Volume 2012, Article ID 859076:7. Pubmed Central PMCID: PMID: 22655201

PMCID: PMC3357951.

48. Youwen Tan GG, Tengli Pan, DanfengWen, Jianhe Gan. Serum MiRNA panel as potential biomarkers for chronic hepatitis B with persistently normal alanine aminotransferase. Clinica Chimica Acta 2015;451: 232-9. Pubmed Central PMCID: PMID: 26483130.

49. KangkangYu G, NingLi. the function of microRNA in hepatitia B virus- related liver disease: from dim to bright. Annals of Hepatology. 2015;July-Agust,14 (4):450-6.

50. Yun Xie1 QY, Azeem Mehmood Butt, Jia Guo, Zhou Tian, Xuli Bao and et.al. Expression profiling of serum microRNA-101 in HBV-associated chronic hepatitis, liver cirrhosis,

and hepatocellular carcinoma. Cancer Biology \& Therapy September 2014; 15(9): 1248-55.

51. Junhao GUI YT, Xinyu WEN, Wenhui ZHANG, Pengjun ZHANG,, GAO J. Serum microRNA characterization identifies miR-885-5p as a potential marker for detecting liver pathologies. Clinical Science 2011;120: 183-93. Pubmed Central PMCID: PMID: 20815808

PMCID: PMC2990200

52. Bo-Xun Jin1 Y-HZ, Wen-Jing Jin2,Xiang-Ying Sun, Gui-Fang Qiao,, Wei Y-Y. MicroRNA panels as disease biomarkers distinguishing hepatitis B virus infection caused 
hepatitis and liver cirrhosis. Scientific Reports 2015;5(15026). Pubmed Central PMCID: PMCID: PMC4601029.

53. Yoshiki Murakami HT, Toshihito Tanahashi, Junko Tanaka, Takashi Kumada, Yoshioka Y. Comprehensive miRNA Expression Analysis in Peripheral Blood Can Diagnose Liver Disease. PLoS ONE 2012;7(10): e48366. Pubmed Central PMCID: PMCID: PMC3485241.

54. J.-Y Wang R-CM, Y.-M Zhang, Y.-J Zhang, H.-Y Liu, Y.-L Qin. Serum microRNA124 is a novel biomarker for liver necroinflammation in patients with chronic hepatitis B virus infection. Journal of Viral Hepatitis. 2015;22:128-36.

55. Yi Zhang YJ, Ruiying Zheng,Yingjun Guo, Yue Wang, Hui Guo and et.al. Plasma MicroRNA-122 as a Biomarker for Viral-, Alcohol-, and Chemical-Related Hepatic Diseases. Clinical Chemistry 2010;56(12):1830-8.

56. Zhu-qing Zhang HM, Nan Wang, Li-na Liang, Li-na Liu, Shu-ming Lu, Yong Luan. Serum microRNA 143 and microRNA 215 as potential biomarkers for the diagnosis of chronic hepatitis and hepatocellular carcinoma. Diagnostic Pathology,BioMed Central. 2014;9(139). Pubmed Central PMCID: PMID: 24993656 PMCID: PMC4226970.

57. Keisaku Sato FM, Shannon Glaser, Gianfranco Alpini. Exosomes in liver pathology. Journal of Hepatology 2016 vol 65 j 213-221. 2016;65:j 213-21.

58. Yao Liu KX, Juan Wen, Min Deng,Jianming Li,Zhibin Hu. A Genetic Variant in MicroRNA-122 Regulatory Region Confers Risk for Chronic Hepatitis B Virus Infection and Hepatocellular Carcinoma in Han Chinese. Journal of Medical Virology 2014;86:1669-74 Pubmed Central PMCID: PMID:24995424.

59. Joon Seol Baea J-HK, Charisse Flerida A. Pasajea, Hyun Sub Cheongb, Tae Hoon Leec ISK, Hyo-Suk Leee, Yoon Jun Kime, Hyoung Doo Shina,. Association study of genetic variations in microRNAs with the risk of hepatitis B-related liver diseases. Digestive and Liver Disease 2012;44: 849- 54. 
Table 1

MicroRNAs function related with hepatitis B virus (CHB, fibrosis/cirrhosis, HCC)

\begin{tabular}{|c|c|c|c|}
\hline MicroRNAs in CHB & $\begin{array}{l}\text { Up /Down } \\
\text { regulated }\end{array}$ & Function & $\begin{array}{l}\text { Referen } \\
\text { ces }\end{array}$ \\
\hline miR-122 & Up & Inhibited viral production & (43) \\
\hline $\mathrm{miR}-372 / \mathrm{miR}-373$ & Up & $\begin{array}{l}\text { hepatic HBV DNA levels } \\
\text { promoted HBV expression }\end{array}$ & $(44)$ \\
\hline $\begin{array}{l}\text { Panel miRNAs(let-7c, miR-23b, } \\
\text { miR-122, and miR-150) }\end{array}$ & & $\begin{array}{l}\text { diagnostic tool occult hepatitis } \\
\text { B virus infection }\end{array}$ & $(45)$ \\
\hline miR-125a-5p & Down & reactivate liver inflammation & (46) \\
\hline $\operatorname{miR}-548, \operatorname{miR}-548 c 5 p$ & $\mathrm{Up}$ & $\begin{array}{l}\text { involved in type I IFN signaling } \\
\text { associated with the proliferation }\end{array}$ & (47) \\
\hline $\begin{array}{l}\text { Panel(miR-21-5p, miR-122-5p } \\
\text { and miR-146a) }\end{array}$ & Up & $\begin{array}{l}\text { of HBVDNA virus and the } \\
\text { progress of the disease and } \\
\text { prediction of the progress of } \\
\text { chronic hepatitis B } \\
\text { as diagnostic biomarkers in } \\
\text { patients with CHB from HCC }\end{array}$ & (34) \\
\hline $\begin{array}{l}\text { MicroRNAs in liver Fibrosis / } \\
\text { Cirrhosis }\end{array}$ & $\begin{array}{l}\text { Up/Down } \\
\text { regulated }\end{array}$ & Function & $\begin{array}{l}\text { Reference } \\
\mathrm{S}\end{array}$ \\
\hline miR-122 & Down & Diagnostic advanced cirrhosis & \\
\hline $\operatorname{miR}-124$ & Down & Diagnostic biomarkers & $\begin{array}{l}(49) \\
(50)\end{array}$ \\
\hline $\begin{array}{l}\text { (miR-199-200, miR-221/222, } \\
\text { miR-214-5p, miR-181b) }\end{array}$ & Down & $\begin{array}{l}\text { moderate to severe liver } \\
\text { necroinflammation } \\
\text { suppressed collagen synthesis, } \\
\text { necroinflammation }\end{array}$ & $(52-55)$ \\
\hline hsa-miR-16 and hsa-let-7a & & $\begin{array}{l}\text { progression of liver fibrosis, } \\
\text { liver fibrosis }\end{array}$ & $(24)$ \\
\hline $\begin{array}{l}\operatorname{miR}-27 a-3 p, \operatorname{miR}-451 a, \operatorname{miR}-1 \\
\operatorname{miR}-18 a-5 p, \operatorname{miR}-29 c-3 p\end{array}$ & & $\begin{array}{l}\text { Expression in patients with } \\
\text { HBV Acute-on-chronic liver } \\
\text { failure (ACLF) compared to in } \\
\text { the Asymptomatic Carrier } \\
\text { (AsCs) }\end{array}$ & (48) \\
\hline miR-106b and miR-181b & & $\begin{array}{l}\text { Differentiated healthy } \\
\text { individual from cirrhosis }\end{array}$ & (56) \\
\hline & & $\begin{array}{l}\text { diagnostic biomarkers in liver } \\
\text { cirrhosis, especially at its }\end{array}$ & \\
\hline
\end{tabular}




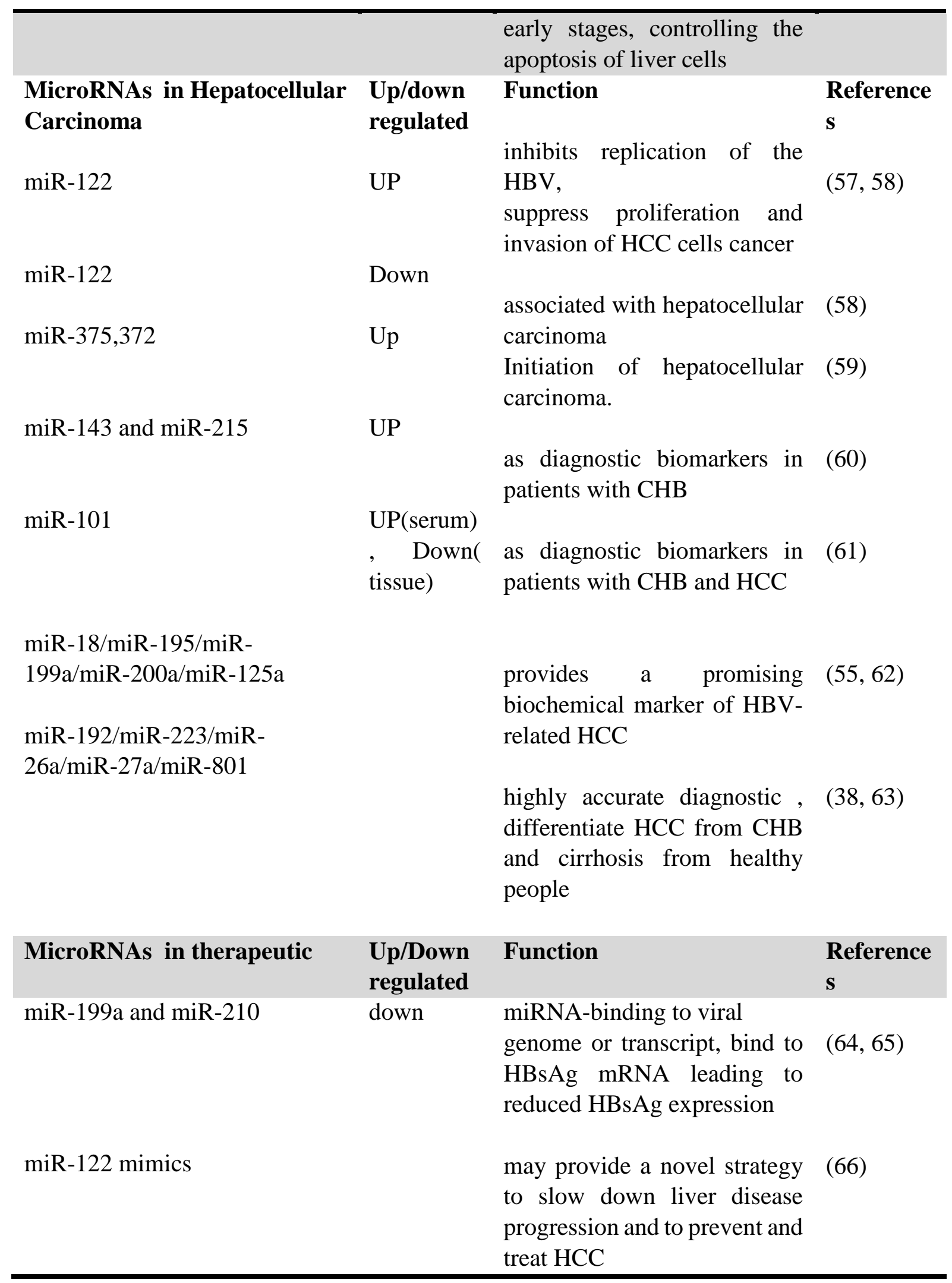




\begin{tabular}{|c|c|c|c|}
\hline & Author & year & conclusion \\
\hline 1 & $\begin{array}{l}\text { Zhang LH1, Zhang } \\
\text { CY2, Dai XZ2, Zhang } \\
\text { J2, Zhang F2. }\end{array}$ & 2017 & $\begin{array}{l}\text { There is no significant association between miR-146a } \\
\text { rs } 2910164 \text { polymorphism and the risk of } \mathrm{HCC} \text {, but } \\
\text { miR-146a rs } 2910164 \text { polymorphism may increase the } \\
\text { risk of HBV-positive HCC. }\end{array}$ \\
\hline 2 & $\begin{array}{l}\text { Li CY1, Pang YY1, } \\
\text { Yang H2, Li J1, Lu } \\
\text { HX1,3, Wang HL1, Mo } \\
\text { WJ1, Huang LS1, Feng } \\
\text { ZB1, Chen G1 }\end{array}$ & 2017 & $\begin{array}{l}\text { MiR-101-1 may be a prospective biomarker for } \\
\text { diagnosis and prognosis of HCC. Potential targets of } \\
\text { miR-101-3p could regulate genesis and development } \\
\text { of HCC and potential therapies in HCC }\end{array}$ \\
\hline 3 & $\begin{array}{l}\text { Zheng L1, Zhuang C1, } \\
\text { Zhao J1, Ming L2. }\end{array}$ & 2017 & $\begin{array}{l}\text { Our results suggest that miR-146a and miR-196a2 } \\
\text { polymorphisms are associated with increased risk of } \\
\text { HCC, especially in Asian. }\end{array}$ \\
\hline 4 & $\begin{array}{l}\text { Li G1, Shen Q, Li C, Li } \\
\text { D, Chen J, He M. }\end{array}$ & 2015 & $\begin{array}{l}\text { Circulating miR-21 has highest level of diagnostic } \\
\text { efficiency among three miRNAs candidate } \\
\text { biomarkers (miR-21, miR-122, and miR-223) for } \\
\text { detection of HCC. }\end{array}$ \\
\hline 5 & $\begin{array}{l}\frac{\text { Wen }}{\mathrm{Y}^{1,2}}, \underline{\text { Han }} \\
\underline{\mathrm{J}}^{1,2}, \underline{\text { Chen }} \mathrm{J}^{3,4}, \underline{\text { Dong }} \\
\underline{\mathrm{J}}^{1}, \underline{\text { Xia }} \underline{\mathrm{Y}}^{5}, \underline{\text { Liu }} \\
\underline{\mathrm{J}}^{4}, \underline{\text { Jiang }}\end{array}$ & 2015 & $\begin{array}{l}\text { meta-analysis revealed that four miRNAs }(\mathrm{miR}-20 \mathrm{a}- \\
5 \mathrm{p} \text {, miR-320a, miR-324-3p and miR-375) could be } \\
\text { used as preclinical biomarkers (pmeta }<0.05) \text { for } \\
\text { HCC }\end{array}$ \\
\hline 6 & $\begin{array}{l}\frac{\text { Xing } \quad \mathrm{TJ}^{1}}{\mathrm{DF}^{2}}, \underline{\text { Jiang }} \\
\underline{\mathrm{ZL}}^{2}, \underline{\text { Huang }} \quad \mathrm{JX}^{2}, \underline{\mathrm{Xu}}\end{array}$ & 2014 & $\begin{array}{l}\text { The detection of miR-122 and miR- } 29 \text { may be useful } \\
\text { in evaluating the inflammatory liver injury and } \\
\text { fibrosis associated with chronic HBV infection. }\end{array}$ \\
\hline 7 & $\begin{array}{l}\text { Sirio Fiorino, } \\
\text { Letizia } \\
\text { Reggiani, } \quad \text { Bacchi- } \\
\text { Visani, } \\
\text { Acquaviva }\end{array}$ & 2016 & $\begin{array}{l}\mathrm{miR}-21, \mathrm{miR}-122, \mathrm{miR}-125 \mathrm{a} / \mathrm{b}, \mathrm{miR} 199 \mathrm{a} / \mathrm{b}, \mathrm{miR}- \\
221, \mathrm{miR}-222, \mathrm{miR}-223, \mathrm{miR}-224 \text {, as biomarkers for } \\
\text { an early diagnosis of HCC development as well as for } \\
\text { the assessment of its prognosis in HBV- or HCV- } \\
\text { positive patients with this type of malignancy, }\end{array}$ \\
\hline 8 & $\begin{array}{l}\text { Jingcheng Yang1, } \\
\text { Shuai Han1, Wenwen } \\
\text { Huang1, Ting Chen2 }\end{array}$ & 2014) & $\begin{array}{l}\text { five up regulated (miR-221, miR-222, miR-93, miR- } \\
21 \text { and miR-224) and four down regulated (miR- } \\
\text { 130a, miR-195, miR-199a } \\
\text { and miR-375) miRNAs. These miRNAs may involve } \\
\text { in the onset and progression of liver cancer and serve } \\
\text { as potential diagnostic and therapeutic targets of this } \\
\text { malignancy. }\end{array}$ \\
\hline 9 & & 2017 & \\
\hline
\end{tabular}




\begin{tabular}{|c|c|c|c|}
\hline & $\begin{array}{l}\text { Yan Ding1,*, Jia-Lai } \\
\text { Yan2,*, An-Ning } \\
\text { Fang3, Wei-Feng } \\
\text { Zhou4 and Ling } \\
\text { Huang1 }\end{array}$ & & $\begin{array}{l}\text { The high frequency expression miRNAs (miR-21, } \\
\text { miR-199 and miR-122) might be more specific for the } \\
\text { diagnosis of hepatocellular carcinoma. }\end{array}$ \\
\hline 10 & $\begin{array}{l}\text { G.Q. Zhou, H. Meng, } \\
\text { J.R. Wang, F.X. Sun, } \\
\text { X.J. Wang, R.B. Wang } \\
\text { and X.B. Wang }\end{array}$ & 2015 & $\begin{array}{l}\text { The meta-analysis results indicated that the miR- } \\
196 \mathrm{a}-2 * \mathrm{~T} \text {, miR-122*del, miR-106b-25*A, and miR- } \\
\text { let-7c*del alleles/carriers increase the risk of hepatitis } \\
\mathrm{B} \text { among the Asian population. However, the miR- } \\
146 \mathrm{a} \text {, miR- } 499 \text {, miR-149, miR-218, and miR-34b/c } \\
\text { polymorphisms may not be linked with the risk of } \\
\text { hepatitis B. }\end{array}$ \\
\hline 11 & $\begin{array}{l}\text { Shao-Liang } \\
\text { Zhu1, }{ }^{*} \text { Jian-Hong } \\
\text { Zhong1,*Wen-Feng } \\
\text { Gong1,*Hang Li2 Le- } \\
\text { Qun Li1 }\end{array}$ & 2016 & $\begin{array}{l}\text { The polymorphism miR-196a } 2 \text { C.T, but not miR- } 499 \\
\text { A.G, may be associated with decreased HBV-related } \\
\text { HCC risk. These conclusions should be verified in } \\
\text { large, well-designed studies }\end{array}$ \\
\hline
\end{tabular}

